\title{
Note on the "sum" of an integral function
}

\author{
By J. M. WhitTaker, University of Liverpool.
}

(Received 14th June, 1934. Read 2nd November, 1934.)

Theorem 1 of a recent paper "On the asymptotic periods of integral functions" 1 can be replaced by the following more precise result.

If $f(z)$ is an integral function of order $\rho$ there is an integral function $g(z)$, of order $\rho$, such that

$$
g(z+1)-g(z)=f(z) .
$$

The improvement consists in showing that, if $\rho<1, g(z)$ can be chosen to be of order $\rho$, not merely of order less than or equal to one.

It is known $n^{2}$ that, if $\rho<1$, a solution of (1) is given by

where

$$
g(z)=\sum_{n=0}^{\infty} n+1
$$

$$
f(z)=\Sigma a_{n} z^{n} . \text { Hence }
$$

$g^{(k)}(0)=\sum_{n=k-1}^{\infty} \frac{a_{n}}{n+1} B_{n+1}^{(k)}(0)=\sum_{n=k-1}^{\infty} a_{n} n(n-1) \ldots(n-k+2) B_{n-k+1}$.

Now

so that

$$
B_{2 m+1}=0, B_{2 m}=(-)^{m+1} \frac{2(2 m) !}{(2 \pi)^{2 m}} \sum_{s=1}^{\infty} \frac{1}{s^{2 m}},
$$

$$
\left|B_{n}\right| \leqq 4 n !(2 \pi)^{-n} \quad(n \geqq 0) .
$$

Moreover, if $1<a<1 / \rho$,

$$
\left|a_{n}\right|<n^{-a n} \quad\left(n \geqq n_{a}\right) .
$$

Hence

$$
\left|g^{(k)}(0)\right|<4 \sum_{n=k-1}^{\infty} n^{-a n} n !(2 \pi)^{k-n-1} \quad\left(k \geqq k_{\alpha}\right)
$$

' Proc. Edinburyh Math. Soc., 3 (1933), 241-258.

"Cf. Nörlund, Sur la "somme" d'une fonction (Paris, 1927), for this and other properties of Bernoulli polynomials. 
Now

$$
\begin{aligned}
\frac{n^{-a n} n !(2 \pi)^{k-n-1}}{(n+1)^{-a(n+1)}(n+1) !(2 \pi)^{k-n-2}} & =2 \pi\left(1+\frac{1}{n}\right)^{a n}(n+1)^{a-1} \\
& >k^{a-1} \quad(n \geqq k-1) .
\end{aligned}
$$

so that

$$
\begin{aligned}
\left|c_{k}\right|=\frac{1}{k !}\left|g^{(k)}(0)\right| & \leqq \frac{4}{k !}(k-1)^{-a(k-1)}(k-1) ! \sum_{s:=0}^{\infty} \frac{1}{k^{8}(a-1)} \\
& <(k-1)^{-a(k-1)} \quad\left(k \geqq k_{a}\right) .
\end{aligned}
$$

Thus

$$
\lim _{k \rightarrow \infty} \frac{\log \left|c_{k}\right|^{-1}}{k \log k} \geqq a .
$$

This is true for every $a<1 / \rho$, so that the order of $g(z)$ cannot be greater than $\rho$. On the other hand it is evident that the order of $g(z)$ cannot be less than $\rho$. 